EGU2020-6206

https://doi.org/10.5194/egusphere-egu2020-6206

EGU General Assembly 2020

(c) Author(s) 2021. This work is distributed under

the Creative Commons Attribution 4.0 License.

\title{
Regulation of dissolved phosphate through incorporation into schwertmannite
}

\author{
Helen E. King ${ }^{1}$, Stan Bakker ${ }^{1}$, Gijs Munnecom ${ }^{1}$, and Felipe Gomez ${ }^{2}$ \\ 1Utrecht University, Utrecht, The Netherlands (h.e.king@uu.nl) \\ ${ }^{2}$ Centro de Astrobiologia, INTA, Madrid, Spain (gomezgf@cab.inta-csic.es)
}

Phosphate is known to absorb strongly to schwertmannite $\left(\mathrm{Fe}_{8} \mathrm{O}_{8}(\mathrm{OH})_{6}\left(\mathrm{SO}_{4}\right) \cdot \mathrm{nH}_{2} \mathrm{O}\right)^{1}$ and as such, schwertmannite has been proposed to limit phosphate in solution in acid mine drainage (AMD) environments. This in turn will limit phosphate availability to the micro-organisms that live in and propagate $A M D^{2}$. Here we have studied sediment samples from the Rio Tinto river in Spain collected during Europlanet field area visit to verify whether phosphate can be incorporated into sulphate-rich minerals in this river. The minerals were identified using X-ray diffraction. Our analyses show that the concentration of phosphate in the river is in the $\mathrm{nM}$ range. Digestion of modern sediments in nitric acid followed by inductively coupled plasma atomic emission spectroscopy (ICP-AES) analysis indicate that sites with sulphate-rich minerals are correlated with elevated phosphate concentrations. In addition, phosphate is also retained in ancient sediments that are dominated by goethite $(\mathrm{FeO}(\mathrm{OH}))$.

We have also conducted experiments to explore the competition between $\mathrm{Fe}^{3+}$, phosphate and sulphate ions in solution as well as the effect of this on schwertmannite nucleation. UV-Vis and Raman spectroscopy demonstrate that contact ion pairs form between $\mathrm{Fe}^{3+}$ and phosphate or sulphate in solution. Particularly, phosphate and sulphate compete for $\mathrm{Fe}^{3+}$ in solution consistent with predictions by the solution speciation modelling program PHREEQC. Our experiments also show that above a critical concentration, phosphate retards the nucleation of schwertmannite. As this critical concentration is above that found in Rio Tinto river fluids, phosphate is expected to have a limited role in schwertmannite precipitation, but, its concentration is regulated by its incorporation into schwertmannite and other sulphate-bearing phases in AMD systems.

References

${ }^{1}$ Eskandarpour et al. 2006, Material Transactions, 1832. ${ }^{2}$ Chen et al. 2015, ISME, 1579. 